Ulfatmi Azlan; Pemertahanan Dan Pergeseran Bahasa Pada Anak Dari Keluarga Multietnis (Studi Kasus

Pada Mahasiswa Jurusan Bahasa Dan Sastra Inggris Fakultas Adab Uin Sts Jambi)

\title{
PEMERTAHANAN DAN PERGESERAN BAHASA PADA ANAK DARI KELUARGA MULTIETNIS (STUDI KASUS PADA MAHASISWA JURUSAN BAHASA DAN SASTRA INGGRIS FAKULTAS ADAB UIN STS JAMBI)
}

\author{
Ulfatmi Azlan \\ State Islamic University of Sulthan Thaha Saifuddin Jambi \\ ulfaazlan@gmail.com
}

\begin{abstract}
This research discusses language maintenance and language shift among children from intermarriage family. It could be found in a society that many children who grow up from intermarriage family have bilingual and multilingual. But in some cases, this condition also become the factors that cause them losing their cultural identity due to their parents do not introduce and teach them their mother tongue language. This condition will be affected the existence of those local languages because it could make them appear or even the worst thing that it could make them become death. Those effects have been found in many local languages in Indonesia in which many local languages have extinct and some of them are going to be extinct. The aims of this research are to describe the phenomenon that appears within the students of English Language and Literature Adab and Humanities Faculty UIN STS Jambi who have intermarriages family's background. Besides that, it also aims to find out the role of parents to decide the language choice used by their children. Since this research lay down from the previous researchers that find out parents are the important role in deciding language choice for their children. Observation and questionnaire are the techniques used in collecting the data. The results show that parents have a role that causes the shift and the maintenance of local languages. In addition, the factors such as bilingual, language's choosing and using at home and migration are the causes of language shift found in English Language and Literature students. But the researcher found that code switching and code mixing are only used by the students for a specific situation where they should elaborate their language with their listeners.
\end{abstract}

Keywords: Language Shift, Language Maintenance, Multietnicht

\section{Latar Belakang}

Setiap bahasa memiliki karakteristik yang berbeda-beda antar satu daerah dengan daerah lainnya bahkan meskipun tertelak dalam letak geografi yang sama juga terdapat perbedaan yang signifikan antar bahasa tersebut. Namun jumlah tersebut 
Ulfatmi Azlan; Pemertahanan Dan Pergeseran Bahasa Pada Anak Dari Keluarga Multietnis (Studi Kasus

Pada Mahasiswa Jurusan Bahasa Dan Sastra Inggris Fakultas Adab Uin Sts Jambi)

akan mengalami penurunan dan dikhawatirkan akan hilang dari masyarakat jika penggunanya tidak lagi peduli dan menggunakan bahasa tersebut dalam kehidupan mereka. Berdasarkan data dari Ethnologue terdapat 726 bahasa daerah yang masih aktif digunakan hingga saat ini serta terdapat sepuluh bahasa daerah dengan jumlah penutur terbanyak di Indonesia, diantaranya: bahasa Jawa, bahasa Sunda, bahasa Madura, bahasa Minangkabau, bahasa Musi, bahasa Bugis, bahasa Banjar, bahasa Aceh, bahasa Bali, dan bahasa Betawi (Liliweri, 2014: 319-322).

Masyarakat Jambi tergolong dalam masyarakat yang multicultural dan heterogen karena terdiri dari berbagai macam etnis, agama, budaya, dan bahasa yang menjadikannya sebagai keunikan tersendiri. Masing-masing kelompok etnis tersebut hidup berdampingan satu dengan lainnya, etnis tersebut anatara lain: Bugis, Melayu, Banjar, Minang, Jawa, Arab, dan Cina. Keanekaragaman tersebut juga memberikan kontribusi pada jumlah bahasa yang digunakan dalam kehidupan social masyarakat. Dalam kesehariannya, bahasa Melayu Jambi merupakan bahasa local dan umum digunakan sehari-hari selain bahasa daerah lainnya sementara bahasa Indonesia berperan sebagai lingua franca yang digunakan oleh masyarakat yang tidak memahami dan menggunakan bahasa Jambi. Begitu pentingnya suatu bahasa dalam kehidupan masyarakat maka kebutuhan akan bahasa juga meningkat terutama dengan penguasaan bahasa asing terlebih pada era globalisasi seperti sekarang ini.

Hal ini menyebabkan bahasa daerah ataupun bahasa local yang digunakan dalam kehidupan sehari-hari semakin terpinggirkan. Ada banyak factor yang menyebabkan bahasa daerah tersebut menjadi terpinggirkan diantaranya karena pernikahan antar suku ynag berbeda latar belakang budaya dan bahasa. Anak yang tumbuh dalam lingkungan yang multikultural akan bersosialisasi dan berinteraksi dengan yang lainnya dengan latar belakang social yang berbeda. Pada beberapa keluarga yang heterogen terdapat beberapa kecendrungan dalam menentukan pilihan bahasa yang digunakan seperti penggunaan bahasa Indonesia dan bahasa daerah. Hal tersebut dapat dimaklumi karena dalam kesehariannya si anak lebih sering berinteraksi dengan ibu ketimbang ayah karena pandangan yang terdapat dalam masyarakat bahwa ayah berperan sebagai pencari nafkah dan ibu berperan sebagai pengurus rumah tangga termasuk di dalamnya mengurus anak-anak. Hal ini menjadi permasalahan bagi si anak karena anak yang terbiasa dengan bahasa nasional (bahasa Indonesia) sehingga tidak mengerti dengan bahasa daerahnya sendiri dan menjadi asing dengan bahasa daerahnya sendiri. Akibatnya hal tersebut juga akan berdampak pada keberlangsungan bahasa itu sendiri karena jika komunitas tersebut tidak lagi menggunakan bahasa daerahnya maka akan menyebabkan bahasa tersebut menjadi punah (language death).

Beberapa penelitian menunjukan bahwa orang tua (ayah dan ibu) sangat berperan penting dalam menentukan pilihan bahasa pada anak serta keberlangsungan suatu bahasa. Penelitian yang dilakukan oleh Mukherjee (2003) menyimpulkan bahwa wanita dalam masyarakat diposisikan sebagai pemertahan dan penyampai bahasa pada generasi penerus sementara pada penelitian Dopke (1990) menemukan bahwa peran ayah lebih besar dalam penurunan kemampuan bahasa anak. Selain itu, 
Ulfatmi Azlan; Pemertahanan Dan Pergeseran Bahasa Pada Anak Dari Keluarga Multietnis (Studi Kasus Pada Mahasiswa Jurusan Bahasa Dan Sastra Inggris Fakultas Adab Uin Sts Jambi)

adanya rasa rendah diri (inferior) ketika menggunakan bahasa daerah juga menjadi factor penyebab terjadinya kepunahan bahasa. Seperti yang diutarakan oleh Setyawan (2011) bahwa kebocoran diglosia dalam beberapa domain keluarga karena dipilihnya bahasa Indonesia sebagai bahasa utama merupakan bukti salah satu indikasi bahwa pemakaian bahasa daerah sedang terjadi pergeseran. Oleh karena itu, maka tulisan ini akan membahas mengenai peran orang tua dalam menentukan pilihan bahasa pada anak yang berasal dari latar belakang keluarga multietnis. Kemudian factor-faktor apa saja menyebabkan terjadinya pergeseran dan pemertahanan serta dalam domain apa saja bahasa yang mayoritas dan minoritas tersebut digunakan.

\section{Landasan Teori}

Kajian tentang pemertahanan dan pergeseran bahasa berkaitan dengan pembahasan sosiolinguistik. Karena hal tersebut berkaitan dengan variasi penggunaan bahasa yang terdapat dalam masyarakat. Sosiolinguistik mengkaji hubungan antara bahasa dan masyarakat yang mengkaitkan dua bidang yang dapat dikaji secara terpisah yaitu struktur formal bahasa oleh linguistic dan struktur masyarakat oleh sosiologi (Wardhaugh 1986:4; Holmes 1992:1; Hudson 1996:2). Pemakaian bahasa dalam masyarakat tidak monolitis tetapi variatif (Bell 1976). Hal ini dapat disimpulkan bahwa dalam masyarakat dapat ditemui penggunaan bahasa yang bervariasi sesuai dengan peran social. Fenomena penggunaan variasi bahasa dalam masyarakat tutur dikontrol oleh factor-faktor social, budaya, dan situasional (Kartomihardjo 1981; Fasold 1984; Hudson 1996; Wijana 1997:5). Dalam hal ini sosiolinguistik bertugas untuk mendeskripsikan hubungan antara gejala pemilihan bahasa dan factor-faktor social, budaya, dan situasional dalam masyarakat dwibahasa atau multilibahasa baik secara korelasional maupun implikasonal.

Kajian mengenai pergeseran dan pemertahanan bahasa merupakan fenomena kebahasaan yang sering dijumpai dalam masyarakat. Terjadinya pergeseran bahasa disebabkan adanya bahasa baru yang digunakan sebagai bahasa komunikasi seharihari yang digunakan untuk berinteraksi dengan masyarakat yang berbeda bahasanya. Pemertahanan bahasa adalah sikap seseorang yang mampu mempergunakan bahasa daerahnya pada fungsi dan ranah tertentu (Sumarsono, 2004: 200). Fishman (1972a: 97) mengatakan bahwa pemertahanan bahasa (language maintenance) bergantung pada ideologi nasional dalam masyarakat atau bergantung paling sedikit pada ideologi yang dimiliki masyarakat yang mempertahankan konteks sosial mereka untuk melawan perubahan yang datang. Faktor-faktor yang mempengaruhi penggunaan dan pemertahanan suatu bahasa diantaranya adalah gejala sosial seperti umur dan jenis kelamin, globalisasi (Romaine, 2000: 83-85; Holmes, 2001: 59). Holmes (2001: 60-64) mengatakan upaya-upaya yang dapat dilakukan untuk mempertahankan penggunaan bahasa adalah sikap positif, kebiasaan menggunakan bahasa daerah, mengikuti ibadah yang bahasa pengantarnya bahasa ibu (bahasa daerah) dan kebiasaan mengunjungi anggota keluarga. Greenfield (1968) dikutip dalam Fishman (1972: 22-23) menyatakan bahwa terdapat lima domain penggunaan 
Ulfatmi Azlan; Pemertahanan Dan Pergeseran Bahasa Pada Anak Dari Keluarga Multietnis (Studi Kasus

Pada Mahasiswa Jurusan Bahasa Dan Sastra Inggris Fakultas Adab Uin Sts Jambi)

bahasa daerah yang sering digunakan, yaitu: keluarga, pertemanan, agama, pendidikan, dan pekerjaan.

Grosjean $(1982$; 107) membuat kategori factor-faktor yang menjadi alasan suatu kelompok mempertahankan bahasanya dan beralih kepada bahasa mayoritas. Factor-faktor yang mempengaruhi pemertahanan dan peralihan bahasa terssebut ada lima yakni aspek social (pernikahan dan imigrasi), sikap kelompok terhadap bahasanya, penggunaan bahasa (domain atau lokasi, fungsi, dan topic pembicaraan, lawan bicara, dan kebijakan pemerintah dalam hukum dan pendidikan terkait dengan bahasa daerah serta factor lainnya seperti dukungan budaya dari negara. Pola imigrasi yang terjadi pada kelompok minoritas mencakup peralihan mereka untuk tetap mempertahankan bahasa mereka dalam waktu yang lama atau beralih secara cepat ke bahasa mayoritas. Berdasarkan penjelasan tersebut dapat dikatakan bahwa sikap masyarakat tutur terhadap pilihan bahasa mereka dipengaruhi oleh factor eksternal. Imigrasi atau perpindahan dari daerah asal ke komunitas baru menyebabkan mereka harus mampu beradaptasi dan menyesuaikan diri dalam hal bahasa dengan lingkungan yang baru. Jaringan social yang sangat erat di dalam kelompok akan mempertahankan konvensi dan norma kelompok termasuk pada bahasa sehingga penjelasan terhadap peran jaringan dapat memperjelas dinamika social yang terjadi dalam kelompok yang menyebabkan terjadinya proses pemertahanan dan peralihan bahasa (Milroy dan Wei, 1995: 139).

Adanya pilihan bahasa yang baru kemudian menyebabkan pengguna bahasa memiliki kemampuan dwibahasa ataupun multilingual. Hal ini dapat disebabkan karena adanya perbedaan bahasa yang ada pada lingkungan luar rumah dengan di rumah. Gumperz (1982:75-81) mengelompokkan jenis alih kode menjadi beberapa jenis, yakni kutipan (quotation), spesifikasi lawan bicara (addressee specification), interjeksi atau pelengkap kalimat (interjection or sentence filler), pengulangan kembali makna suatu pesan dalam bahasa lain (reiteration), dan penjelas pesan (message qualification).

\section{Tinjauan Pustaka}

Beberapa penelitian yang telah dilakukan terkait dengan pembahasan pemertahanan dan pergeseran bahasa yakni: pertama, penelitian yang dilakukan oleh Herbert Igboanusi and Hans-Georg Wolf (2009) yang berjudul "The role of ethnically mixed marriages in language shift: a case study of Nigeria's minority languages". Perkawinan campuran dapat menyebabkan terjadinya pergeseran bahasa di rumah karena hal tersebut dapat menyebabkan perubahan pola penggunaan bahasa di kalangan minoritas penutur bahasa dan anak-anak mereka. Dapat dikatakan bahwa kemungkinan untuk melestarikan bahasa minoritas lebih besar jika dibandingkan perkawinan yang terjadi antar individu yang berbicara dengan bahasa yang sama dengan pasangan yang berbicara dengan bahasa yang berbeda.

Penelitian ini dilakukan dengan menggunakan data kuesioner dari orang tua dari latar belakang perkawinan antar etnis. Tujuan dari penelitian ini adalah untuk 
Ulfatmi Azlan; Pemertahanan Dan Pergeseran Bahasa Pada Anak Dari Keluarga Multietnis (Studi Kasus

Pada Mahasiswa Jurusan Bahasa Dan Sastra Inggris Fakultas Adab Uin Sts Jambi)

mengetahui bagaimana pernikahan campuran berkontribusi pada pergeseran bahasa dari bahasa minoritas ke bahasa Inggris (bahasa resmi Nigeria), Pidgin Nigeria (informal lingua franca) dan bahasa standar (yaitu Hausa, Igbo dan Yoruba) dalam domain rumah tangga. Hasilnya menunjukkan bahwa masa depan bahasa minoritas sangat bergantung pada peran keluarga dan nilai yang melekat pada identitas etnis minorita kaum muda terutama yang berlatar belakang keluarga campuran.

Kesimpulan dari penenlitian ini adalah pemertahanan bahasa minoritas akan sulit tanpa adanya kerjasama antar anggota keluarga. Baik orang tua maupun anakanak sangat penting dalam pemertahanan bahasa. Anak-anak tidak akan berperan dalam melestarikan bahasa ibunya selama orang tua tidak berbicara dengan menggunakan bahasa mereka atau mendorong anaknya untuk menggunakannya dalam keseharian mereka karena selama bahasa mayoritas selalu dikaitkan dengan masalah politik, sosial dan keuntungan ekonomi sementara bahasa minoritas tidak, maka bahasa campuran yang digunakan dalam suatu rumah tangga akan terus bergeser dan hal tersebut berimplikasi pada masa depan bahasa minoritas. Untuk membendung pergeseran bahasa minoritas, maka perlu dibuat strategi untuk meningkatkan penggunaan bahasa minoritas tersebut misalnya dengan menerapkan penggnaannya pada ranah bergengsi seperti dalam dunia pendidikan, media dan parlemen.

Penelitian kedua dilakukan oleh Nurhayati Sitorus dengan judul Pemertahanan Bahasa Pakpak Dairi di Kabupaten Dairi. Penelitian ini membahas pemertahanan bahasa Pakpak Dairi di Kabupaten Dairi. Fokus penelitian ini adalah kondisi pemertahanan bahasa Pakpak Dairi, faktor-faktor yang mempengaruhi pemertahanan bahasa Pakpak Dairi, dan upaya pemertahanan bahasa Pakpak Dairi. Responden yang dijaring dalam penelitian ini sebanyak 99 yang diambil melalui teknik aeak berlapis dan dibagi ke dalam tiga kelompok, yaitu kelompok remaja, kelompok dewasa, dan kelompok orang tua. Data diperoleh melalui kuesioner, observasi, dan wawancara. Data dianalisis dengan menggunakan analisis statistik deskriptif dan analisis Miles dan Hubennan.

Hasil penelitian menunjukkan bahwa kondisi pemertahanan bahasa Pakpak Dairi sekarang pada kelompok remaja sudah tidak bertahan. Pemertahanan bahasa Pakpak Dairi pada kelompok remaja sangat rendah di semua ranah, baik ranah rumah, ranah luar rumah, ranah gerejalmesjid, dan ranah sekolah. Selanjutnya, kondisi pemertahanan bahasa Pakpak Dairi pada kelompok dewasa dan kelompok orang tua banya bertahan pada ranah tertentu, yakni ranah gerejalmesjid. Namun, kondisi pemertahanan bahasa Pakpak Dairi pada ranah rumah, ranah luar rumah, dan ranah pekerjaan sudah tidak bertahan. Faktor-faktor yang mempengaruhi pemertahanan bahasa Pakpak Dairi berasal faktor intralinguistik dan faktor ekstralinguistik. Adapun factor intralinguistik yang dapat mempengaruhi pemertahanan bahasa Pakpak Dairi adalah alih kode dan eampur kode. Selanjutnya, faktor ekstralinguistik yang dapat mempengaruhi pemertahanan bahasa Pakpak Dairi adalah identitas, kepercayaan diri, kesetiaan, kebanggaan budaya, migrasi, konsentrasi tempat tinggal, jumlah penutur, agama, mengikuti ibadah di luar GKPPD, umur, interlokutor, ranah, pekerjaan, 
Ulfatmi Azlan; Pemertahanan Dan Pergeseran Bahasa Pada Anak Dari Keluarga Multietnis (Studi Kasus Pada Mahasiswa Jurusan Bahasa Dan Sastra Inggris Fakultas Adab Uin Sts Jambi)

perkawinan campuran, dan kebiasaan menghubungi famili di kampung halaman. Upaya yang dilakukan dalam mempertahankan bahasa Pakpak Dairi agar pemuda memiliki sikap positif terhadap daerah dalam diri masing-masing individu, menggunakan bahasa Pakpak Dairi dalam kehidupan mereka sehari-hari, mengajari dan menggunakan bahasa Pakpak Dairi kepada anak-anak di rumah, menggunakan bahasa dan budaya Pakpak dalam adat-istiadat, menjadi anggota dalam suatu lembaga, menjadikan bahasa Pakpak Dairi sebagai mata pelajaran muatan lokal di sekolah, mengikuti ibadah di GKPPD, mengikuti ibadah di mesjid yang menggunakan bahasa Pakpak Dairi mengikuti acara kebaktian kumpulan setiap mingguannya, dan kebiasaan mengunjungi famili.

\section{Metode Penelitian}

Kajian mengenai pemertahanan dan pergeseran bahasa merupakan kajian Sosiolinguistik dimana dalam penelitian ini menitikberatkan pada variasi bahasa yang digunakan dengan melibatkan unsur-unsur diluar bahasa yang menyebabkan terjadinya pergeseran dan pemertahanan bahasa. Penelitian ini merupakan penelitian kualitatif yang melibatkan kata-kata dalam menjelaskan pergeseran dan pemertahan bahasa yang terjadi pada anak dengan latar belakang keluarga multietnis. Yang menjadi responden dalam penelitian ini adalah sejumlah mahasiswa yang berusia antara 18-22 tahun. Mereka sedang menempuh pendidikan di kampus UIN STS Jambi.

Tabel 1

Daftar Responden

\begin{tabular}{|c|c|c|c|c|}
\hline \multirow{2}{*}{ No. } & \multirow{2}{*}{ Inisial Nama } & \multirow{2}{*}{ Usia } & \multicolumn{2}{|c|}{ Latar Belakang Etnis } \\
\cline { 4 - 5 } & & 20 & Ayah & Ibu \\
\hline 1 & DRA & 21 & Merlembang & Jambi \\
\hline 2 & HN & 21 & Banjar & Palembang \\
\hline 3 & MM & 19 & Palembang & Jambi \\
\hline 4 & MK & 21 & Batak & Minang \\
\hline 5 & HJ & 20 & Banjar & Jawa \\
\hline 6 & RR & 20 & Jawa & Sunda \\
\hline 7 & AT & 20 & Batak & Jawa \\
\hline 8 & PAN & & & \\
\hline
\end{tabular}

Dalam penelitian ini, metode yang digunakan dalam pengumpulan data adalah metode simak yakni metode yang dilakukan dengan menyimak. Menyimak disini tidak hanya digunakan dalam bahasa lisan tapi juga dalam bentuk tertulis (Mahsun, 2005: 90). Dalam hal ini peneliti menyimak penggunaan bahasa yang digunakan oleh anak yang memiliki latar belakang keluarga multietnis dengan menggunakan teknik sebagai berikut: teknik simak bebas libat cakap. Pada teknik simak bebas libat cakap 
Ulfatmi Azlan; Pemertahanan Dan Pergeseran Bahasa Pada Anak Dari Keluarga Multietnis (Studi Kasus Pada Mahasiswa Jurusan Bahasa Dan Sastra Inggris Fakultas Adab Uin Sts Jambi)

ini peneliti hanya berperan sebagai pengamat penggunaan bahasa oleh informannya serta tidak terlibat dalam peristiwa pertuturan bahasa yang sedang diteliti (Mahsun, 2005: 91). Dalam hal ini peneliti menyimak penggunaan bahasa yang digunakan oleh anak-anak dari keluarga multietnis tersebut ketika berada di rumah dan diluar rumah ketika berinteraksi dengan anak-anak lain yang berasal dari latar belakang bahasa yang berbeda serta alih kode dan campur kode yang digunakan dalam keseharian mereka.

Data yang telah didapatkan kemudian diklasifikasikan untuk dianalisis dengan menggunakan metode padan (Sudaryanto, 1993: 13). Metode padan yang digunakan dalam penelitian ini adalah metode padan ekstralingual yakni menghubungbandingkan hal-hal diluar bahasa seperti referen, konteks tuturan: konteks sosial pemakaian bahasa, penutur bahasa yang dipilah misalnya berdasarkan gender, usia, kelas sosial, dan sebagainya (Mahsun, 2005: 236). Setelah data tersebut didapatkan kemudian dipilah untuk kemudian dianalisis. Data tersebut kemudian disajikan dalam bentuk metode formal dan metode informal yaitu perumusan dengan menggunakan kata-kata biasa termasuk penggunaan terminology yang bersifat teknis dan perumusan dengan menggunakan tanda-tanda atau lambang (Sudaryanto, 1993: 144) dalam Mahsun (2005: 116).

\section{Pembahasan}

Berdasarkan data yang didapat dari responden ditemukan bahwa hampir sebagian besar responden dengan latar belakang keluarga yang multietnis diantaranya: EP dengan latar belakang keluarga dimana ayah beretnis Jawa dan ibu beretnis Minang, LS dengan latar belakang keluarga dengan ayah beretnis Sunda dan ibu beretnis Melayu, PS dengan latar belakang ayah dan ibu sama-sama beretnis campuran Jawa-Melayu Jambi, DRA dengan latar belakang ayah beretnis Melayu Palembang dan ibu beretnis Melayu Jambi, MWA dengan latar belakang ayah beretnis Bugis dan ibu beretnis campuran Jawa Palembang, AHP dengan latar belakang ayah beretnis Sunda dan ibu beretnis Jawa, HN dengan ayah beretnis campuran Minang Jambi dan ibu beretnis Jawa, AI dengan latar belakang ayah beretnis Melayu Jambi dan ibu beretnis Jawa, QAS dengan latar belakang ayah beretnis Melayu Jambi dan ibu beretnis Minang, serta MM dengan latar belakang ayah beretnis Banjar dan ibu beretnis Melayu Palembang.

Dari analisis data yang dilakukan mengenai pergeseran dan pemertahanan bahasa pada anak dengan latar belakang keluarga (orang tua) yang multietnis ditemukan bahwa terjadi fenomena pergeseran dan pemertahanan bahasa dimana pergeseran bahasa didapatkan pada dua responden dengan latar belakang orang tua etnis Jawa dan Sunda serta Banjar dan Jawa. Dari kedua responden tersebut dapat ditarik kesimpulan telah terjadi pergeseran bahasa karena pilihan bahasa yang digunakan sebagai komunikasi sehari-hari di rumah adalah bahasa dominan yakni bahasa Jambi sementara bahasa daerah tidak diperkenalkan dan digunakan di rumah. Dalam hal ini peran orang tua dalam mewariskan bahasa daerah kepada mereka tidak berjalan karena keduanya tidak menguasai bahasa daerahnya. 
Ulfatmi Azlan; Pemertahanan Dan Pergeseran Bahasa Pada Anak Dari Keluarga Multietnis (Studi Kasus Pada Mahasiswa Jurusan Bahasa Dan Sastra Inggris Fakultas Adab Uin Sts Jambi)

Pada responden lainnya yakni dua responden ditemukan bahwa mereka menguasai bahasa daerah dari kedua orang tuanya dan dalam komunikasi sehari-hari di rumah mereka menggunakan alih kode dan campur kode dengan anggota keluarga lainnya. Sementara empat orang responden lainnya hanya menguasai dan memahami salah satu bahasa daerah dari orang tuanya yakni bahasa daerah dari ibu, factor kedekatan dan intensitas pertemuan menjadi alasan mereka lebih menguasai bahasa daerah ibu sedangkan bahasa daerah ayah tidak terlalu dikuasai karena mereka hanya memahami beberapa kata saja dan bahasa tersebut juga hanya digunakan dan didengar ketika ada acara pertemuan keluarga.

Adapun factor-faktor yang menyebabkan trejadinya pergeseran dan pemertahanan bahasa adalah karena adanya migrasi dari daerah asal sehingga bahasa yang digunakan menyesuaikan dengan bahasa yang mayoritas digunakan di tempat tinggal yang baru. Selain itu pemilihan dan penggunaan bahasa yang digunakan di rumah yakni bahasa dominan juga menjadi penyebabnya, serta adanya penggunaan bahasa yang berbeda-beda pada konteks tertentu sehingga mereka harus menggunakan alih kode dan campur kode. Sementara pengenalan dan penggunaan bahasa daerah pada ranah keluarga menjadi factor penting dalam menjaga keberadaan bahasa tersebut agar tidak menjadi hilang.

Tabel 2

Alasan dan Penggunaan Bilingual

\begin{tabular}{|c|c|c|c|}
\hline No. & Responden & Alasan Bilingual & Penggunaan Bilingual \\
\hline 1 & DRA & kekurangan kosakata & $\begin{array}{c}\text { Menggunakan secara utuh } \\
\text { dalam kalimat }\end{array}$ \\
\hline 2 & PAN & $\begin{array}{c}\text { Perbedaan status dengan lawan } \\
\text { bicara }\end{array}$ & $\begin{array}{c}\text { Menggunakan secara utuh } \\
\text { dalam kalimat }\end{array}$ \\
\hline 3 & RR & kekurangan kosakata & $\begin{array}{c}\text { Menggunakan secara utuh } \\
\text { dalam kalimat }\end{array}$ \\
\hline 4 & MM & kekurangan kosakata & $\begin{array}{c}\text { Menggunakan secara utuh } \\
\text { dalam kalimat }\end{array}$ \\
\hline
\end{tabular}


Ulfatmi Azlan; Pemertahanan Dan Pergeseran Bahasa Pada Anak Dari Keluarga Multietnis (Studi Kasus Pada Mahasiswa Jurusan Bahasa Dan Sastra Inggris Fakultas Adab Uin Sts Jambi)

\begin{tabular}{|c|c|c|c|}
\hline 5 & $\mathrm{HN}$ & $\begin{array}{l}\text { a.kehadiran orang lain } \\
\text { b. } \\
\text { topic pembicaraan yang } \\
\text { dibicarakan sifatnya rahasia } \\
\text { c.kekurangan kosakata }\end{array}$ & $\begin{array}{l}\text { Menggunakan secara utuh } \\
\text { dalam kalimat }\end{array}$ \\
\hline 6 & MK & kekurangan kosakata & Hanya beberapa kata saja \\
\hline 7 & $\mathrm{HJ}$ & $\begin{array}{c}\text { Menyesuaikan dengan lawan } \\
\text { bicara }\end{array}$ & $\begin{array}{l}\text { Menggunakan secara utuh } \\
\text { dalam kalimat }\end{array}$ \\
\hline
\end{tabular}

\section{References}

Buska, W., Prihartini, Y., \& Hasnah, N. 2018. Analysis of Students' Arabic Proficiency for Vocabulary Mastery in State Islamic Junior High School in Muaro Jambi. Innovatio: Journal for Religious Innovation Studies, 18 (1), 51-62.

Crystal, David. 2000. Language Death. United Kingdom: Cambridge University Press.

Fishman, Joshua. 1972. Language and Sociocultural Change. California: Academic Press.

1972. The Relationship between Micro- and Macro- Sociolinguistics in the Study of who Speaks What language to Whom and When. In J.B. Pride and Janet Holmes (eds). Sociolinguistics: Selected Readings. Hammondsworth: Penguin Books Ltd. . 1972. Language Maintenance and Language Shift. Dalam J.A. Fishman Language in the Sociocultural Change. Stanford: Stanford University Press.

Gumperz, Jhon J. 1982. Language and Social Identity. USA: Cambridge Press University.

Grosjean, F. 1982. Life with Two Languages: An Introduction to Billingualism. Cambridge, Massachusetts, London, and England: Harvard University Press.

Holmes. 2001. An Introduction to Sociolinguistic. New York: Pearson Education. Hudson, Richard A. 1996. Sociolinguistics. Cambridge: Cambridge University Press. Igboanusi, Herbert and Hans-Georg Wolf. 2009. The Role of Ethnically Mixed Marriages in Language Shift: a Case Study of Nigeria's Minority Languages.

SOLS vol 3.32009 hal. 451-464 DOI: 10.1558.

Kramsch, Claire. 1998. Language and Culture. Oxford: Oxford University Press. Liliweri, Allo. 2014. Pengantar Studi Kebudayaan. Bandung: Nusa Media. 
Ulfatmi Azlan; Pemertahanan Dan Pergeseran Bahasa Pada Anak Dari Keluarga Multietnis (Studi Kasus

Pada Mahasiswa Jurusan Bahasa Dan Sastra Inggris Fakultas Adab Uin Sts Jambi)

Mahsun. 2005. Metode Penelitian Bahasa. Jakarta: PT Raja Grafindo Persada.

Mackey, M. 1968. The Description of Billingualism. In J. Fishman (ed) Readings in the Sociology of Language. The Hauge: Mouton.

Prihartini, Y., \& Wahyudi, W. (2018). The Development of Integrated Learning Model To Improve Language Skills at Arabic Language. IJER (Indonesian Journal of Educational Research), 3(1), 9-14.

Prihartini, Y., Wahyudi, W., Aliasar, A., Mukhaiyar, M., \& Ungsi, A. O. M. (2018). The Development of Arabic Learning Model by Using Multimedia of Computer at UIN STS Jambi. Al-Ta lim Journal, 25(2), 135-143.

Renkema, Jan. 1993. Discourse Studies; an Introductory Textbook. Amsterdam: John Benjamins Publishing Company.

Romaine. 2000. Language in Society: An Introduction to Sociolinguistics. New York: Oxford University Press.

Setyawan, Aan. 2011. Bahasa Daerah dalam Perspektif Kebudayaan dan Sosiolinguistik: Peran dan Pengaruhnya dalam Pemertahanan dan Pergeseran Bahasa. International Seminar Language Maintanance and Shift. July 2, 2011. UNDIP University.

Sudaryanto.1990. Aneka Konsep Kedataan Lingual dalam Linguistik. Yogyakarta: Duta Wacana University Press.

Sugiono. 2012. Memahami Penelitian Kualitatif. Jakarta: Alfabeta.

Sumarsono. 2004. Sosiolinguistik. Yogyakarta: Sabda.

Sitorus, Nurhayati, Dwi Widayati, and Masdiana Lubis. 2014. Pemertahanan Bahasa Pakpak Dairi di Kabupaten Dairi. Kajian Linguistik Program Studi Linguistik FIB USU hal. 94-107 1SSN 1693-4660 Tahun ke-12, No2

Tondo, Fanny Henry. 2009. Kepunahan Bahasa-Bahasa Daerah: Faktor Penyebab Dan Implikasi Etnolinguistis. Jurnal Masyarakat \& Budaya, Volume 11 No. 2 Tahun 2009 hal. 277-295

Triyono, Sulis. 1998. Korespondensi Proto Melayu Polinesia dengan Bahasa Jawa dan Bahasa Indonesia. Yogyakarta: PS Linguistik FIB UGM.

Wahyudi, W., \& Prihartini, Y. (2019, April). Development of Arabic Learning Material Based on Eclectic Method. In 3rd Asian Education Symposium (AES 2018). Atlantis Press

Wei, Li and Lesley Milroy. 1995. Conversational code-switching in a Chinese community in Britain: A Sequential Analysis. Journal of Pragmatics Volume 23, Issue 3, March 1995 hal. 281-299. https://doi.org/10.1016/03782166(94)00026-B 